\title{
Impact of Fuel and Energy Complex on Sustainable Development of Mineral Extracting Regions: the World Experience
}

\author{
Anna Barbara ${ }^{1, *}$, and Lyubov Sluder ${ }^{2}$ \\ ${ }^{1}$ Kuzbass State Technical University, Mezhdurechensk Branch, 652881, pr. Stroiteley, 36, \\ Mezhdurechensk, Russia \\ ${ }^{2}$ East Carolina University, 27858, E 5th St., Greenville, NC, USA
}

\begin{abstract}
The fossil fuel sectors and export of its products occupy a leading position in the economy of many countries and directly affect the sustainability of national economies. Therefore, in the long term an adequate vision of the development of these sectors is of great importance in forecasting and planning the strategic development of these countries. The wide use of coal fuel in the world energy consumption will remain for quite a long time; however, the environmental problems associated with its production are a serious factor hindering the possibility of a transition to the sustainable development of coal-producing regions. There is an obvious need for a balanced approach in developing greater industrial potential while protecting the environment. The world is slowly moving away from coal as other forms of energy have become cheaper and environmental concerns mount. The authors analyzed the world and domestic experience in the initiation, promotion and implementation of projects that contribute to the sustainable development of the leading mining regions of the world. The ability of the authorities to clearly define strategic priorities, improve the business climate, effectively distribute and improve the quality of regional resources and infrastructure creates the prerequisites for enhancing the sustainable competitive advantages of a region, business, and public welfare.
\end{abstract}

\section{Introduction}

The concept of sustainable development is becoming increasingly important in connection with the entry of the world economy on the path of systemic transformation. In the context of global challenges, new approaches of business structures to the management of resources and risks are being formed, and a search is under way for new tools to influence the economy, society, and ecology. The Sustainable Development Goals (SDGs) up to 2030 adopted at the UN Summit in September, 2015, and officially entered into force on January $1,2016$.

Global development goals are an incentive for the growth of companies, motivation to introduce innovations in the field of management, information technology, and production.

${ }^{*}$ Corresponding author: barbara ad@mail.ru 
Although the SDGs do not have a legally binding force, in Russia and the world a national strategy is beginning to take shape combining goals for achieving economic efficiency, social justice and environmental security. Russian business is also actively involved in shaping new approaches to the mission, role and objectives of the business and its partnerships in the context of sustainable development by updating business strategies including the social and environmental dimension of profits, revising the fundamentals of corporate management and expanding the scope of business responsibility, implementing effective practices in the field of corporate environmental and social responsibility, system philanthropy, corporate volunteering. Regional policies should also be aimed at achieving these goals, rely on national analysis and facilitate follow-up at the global level.

According to the BP's Statistical Review of World Energy in the global fuel and energy balance, the share of coal generation is about $40 \%$. It is the cheapest source of energy for consumers. Coal dominates the global energy arena due to the abundance of resources, and widespread availability worldwide. Population growth in developing countries in the AsiaPacific region (APR) will further boost consumption of the cheapest and most affordable energy resources. The volatility of coal market conditions and prices of coal products are major constant risks of the global coal industry. The task of developing a long-term strategy for the sustainable development of coal-mining regions is becoming an urgent issue. Below, the authors analyzed the socio-economic development strategies of the leading mining regions of the world.

\section{Materials and Methods}

In this study, the authors consider the concept of "sustainable development" in the context of the coal-mining region, focusing on the economic, environmental and social components of this process, using the methods of regional and system analysis. The object of the study is a coal mining region. The subject of the research is the impact of the fuel and energy complex of the region on the sustainable development strategy. As a result of the analysis of world experience, the authors proposed the main provisions of the concept of the sustainable development of coal-mining regions, provided a rationale for the application of local approaches to the development of models for the sustainable development of coalmining territories. It is this method that will allow the region to build an effective socioeconomic sustainable development strategy focused on achieving the following goals: economic growth in the region, social stability while ensuring environmental protection, preserving biodiversity, and combating climate change.

\section{Results and Discussion}

The forecasts for the development of the world coal market are quite favorable, according to the forecast of the agency Wood Mackenzie, by 2020 coal consumption in the world will reach 4.5 billion tons of oil equivalent and will be ahead of oil consumption (4.4 billion tons). According to the research agency, China and India will play the main role in increasing the demand for coal in the future, and China will account for two thirds of the growth in coal consumption.

According to the BP Statistical Review of World Energy (June 2018), China remains the leader in coal production, accounting for $45.6 \%$ of global coal production, India is second with $9.3 \%$, and the United States is $9.1 \%$ coal mined in the world, the fourth in the list is Australia with a share of $6.2 \%$, Russia is located in sixth place with a figure of $5.3 \%$. Volumes of coal production by the largest countries-coal producers are shown in Figure 1. 


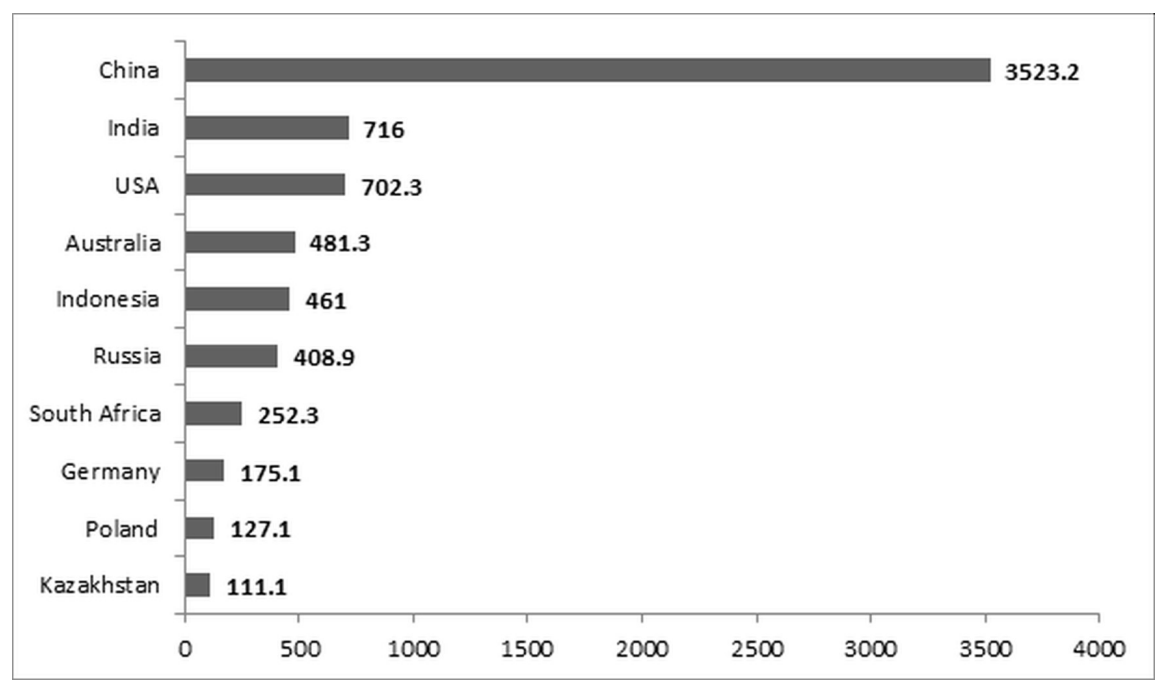

Fig. 1. World coal production in 2017, million tons.

According to the UN Statistics Department (excluding the United States, which did not report data for 2017), Australia is the largest exporter of coal $(41.1 \%$ of world coal exports), Indonesia is second indicator (24.1\%), and Russia is in third place (18\% of world exports). The leading importers of coal are the countries of the Asia-Pacific region (India, Japan, Korea, China), as well as Germany, Turkey, Brazil, Spain and the United Kingdom.

Taking into account the situation on the world coal market, it is important to determine the qualitative and quantitative characteristics of the socio-economic, environmental, and innovative component of the region's sustainable development. Since each region has different mining and geological features, the level of the economy, social welfare, mining technology and the development of coal mining areas require the implementation of a local model of sustainable development. A development program will be economically efficient, socially oriented and environmentally acceptable only if this condition is met. Below we consider the existing global experience.

\subsection{Australian experience}

The economic growth of the Queensland has brought substantial opportunities, but it has also triggered concerns on a range of issues regarding community health and wellbeing [1]. The mining industry boom in Queensland led the Queensland Government to announce their Sustainable Resources Communities Policy in September 2008. The Queensland government is also the throes of developing better policy tools for regulating social impacts on Queensland resource communities.

Driven by the global demand for coal and other mineral resources, the Bowen Basin is one of Australia's fastest growing industrial and mining regions, is a major contributor to both Queensland and Australia's economy. More than 25 billion tons of measured and indicated coal resources have been located in the Bowen Basin and these typically provide over $85 \%$ of Queensland's annual coal product. Queensland's mining and energy resources represent $80 \%$ of all state exports [2]. Queensland is the world's largest seaborne exporter of metallurgical coal, with over $90 \%$ of its saleable coal exported [1]. Last decade more than 50 new mines were also proposed. Although, existing mines have life expectancies generally exceeding 20 years and measured and indicated resources in the area are 
extensive which indicates that coal mining will continue to play a critical role in the social and economic functioning of the Bowen Basin into the future [1].

The socio-economic profile of the Bowen Basin region is strongly shaped by the mining sector via its influences on demographic, economic and health statistics and explained below [1].

Demography: $40 \%$ of the male workforce is employed in the mining, construction or manufacturing industries, and also more than $20 \%$ of jobs are taken up by non-residents who commute on shift rosters. Quantifying the non-resident population is a serious issue for the region, since demand for services and planning/supply of community services and soft infrastructure is set by estimated resident population statistics. It's clear need for regular monitoring of key statistics in the area, using a tailored approach that accounts for the large non-resident population, and for that information to be made readily available to regional planning groups and government. There is a gender imbalance due to high male population driven by regional industry specifics and due to significant loss of youth looking for better opportunities.

The health has the lack of infrastructure availability, medical practitioners are in short supply in the region, the regional coastal hubs are the only centers in Bowen Basin where residents can access healthcare facilities and services beyond basic level care. All private hospital beds are restricted to the coastal centers. The Bowen Basin has a high number of solo general practitioners (GPs). Workloads for GPs are high; they must cater to a large number of patients often with little or no relief staff. Many specialist services are simply unavailable. For example, pediatric, gynecology and obstetrics services are extremely limited in smaller centers.

Economy: coal is one of Queensland's most important export commodities, and the state receives strong benefits from the coal sector through financial returns, increased employment opportunities and regional development. Considering the overall positive benefits from the sector, however these benefits have not always reflected in the fortunes of the community that host resource sector activity. Thus, long-term programs are needed, which also includes wider 'social investment', initiatives undertaken by mining companies to compensating regional communities for the negative social impacts they may experience. Obvious the imbalance apparent between the value taken out of the region and what is paid to government, compared with the compensating value being put back into the social, economic and environmental infrastructure for the region. The public expectation is now that mining operations will contribute to the overall sustainability of the regions within which they are active [3].

Infrastructure: the mining industry relies on modern and efficient transport infrastructure in order to move its product from mine to market and is one of the utmost importance to the development of the Bowen Basin. An expansion to the current transport network will be required in Queensland to meet expecting 400 million tons capacity: current capacity is 188 and 213 million tons for the rail and port systems, respectively.

Housing is an issue of critical importance across the Bowen Basin: it is a basic need, and lack of appropriate housing can cause blockages elsewhere through its influence on economic status. In the Isaac, Central Highlands and Whitsundays areas, over half the coalmining workforce is housed in accommodation provided by mining companies (hostels, camps or houses), but demand for more beds continues to grow strongly as the shift workers base increases. Despite strong demand for accommodation, residential dwelling activity is not particularly high across the Bowen Basin. A number of other issues are also evident: contractors are reluctant to invest, short-term residents are reluctant to purchase homes where they do not expect to live permanently, demand for rental premises is high, and lack of information on housing demand is also barrier to approving new housing developments in the Bowen Basin. 
Public transportation is another important issue in the Bowen Basin: the great distance combined with an ageing population and the need to visit the provincial service hubs for many basic and specialist health services means that an accessible public transport system is critical. Transportation services are viewed as a major limiting factor in the Basin in general. The lack of integration of the transport services between existing providers is a commonly expressed concern and limits the potential accessibility of the region.

The loss of youth from the community also represents a major challenge for many communities of the Bowen Basin, due to the almost complete lack of entertainment and recreation infrastructure. Many social issues relating to youth stem from a lack of organized activity and events, which leads to growth in crime, drug and alcohol abuse.

Recommendations have been developed for each of the strategic issues described above. Some key recommendations for achieving sustainable regional development in the Bowen Basin are summarized below.

1. Develop strategies and actions to ensure currency and adequacy of statistics for planning purposes; ensure consistency in the use of data, preferably via standardized reporting regimes.

2. Consider new ways to address the housing issues in the Bowen Basin including gathering sound data on housing demand, housing affordability, rental cost and availability. 3. Consider new ways to address the shortages of hospital beds and the acute shortages in medical practitioners and allied health professionals in the region. Develop and use effective indices to monitor community health.

4. Identify mechanisms to better address socio-economic mining consequences.

5. Ensure collection and redistribution of revenue from mining is undertaken in a transparent, accountable and equitable manner.

6. Ensure environmental safety in the region (reduce of anthropogenic loads due mining, solve the problems of emissions from fuel use, develop the long-term programs for the water resources conservation).

7. Focus on gender imbalances and the needs of youth, support skilled migrants and their families to assist in addressing skills shortages.

8. Develop infrastructure: transport services for the region, entertainment and recreation infrastructure.

9. Develop and use effective indices to monitor community wellbeing; use wellbeing data for delivery of targeted support and services to regional communities to address declining livability.

10. Develop of social partnerships with business (clarify the roles and responsibilities of each stakeholder and collaborate; develop the social programs; develop business networks, clusters and alliances; fund to agriculture sector for carbon offsets emissions; discover the target programs to engage small and medium enterprises and to improve local supply capacity, business acumen, quality assurance, access to venture capital).

\subsection{Russian experience}

The Kuznetsk coal basin (Kuzbass) is the most prominent coal mining region of Russia. According to the Central dispatch control of fuel and energy complex 58.1\% of Russia's overall coal production came from this region in 2018. The measured and indicated resources in the basin reserves of 130 billion tons with a total coal reserve estimated at 631 billion tons. About $40 \%$ of coal produced in Kuzbass is exported, which determines the strong dependence of enterprises on world fossil fuel prices [4]. Over the past years production and consumer waste are being increased by $6-8 \%$ per year in the Kemerovo region (according to the official statistics). The current state of the areas of intensive coal mining indicates the depletion of the ecological potential of the natural environment. 
Mainly, this is due to the increase of coal production, which exceeded 250 million tons in 2018 (according to the Central dispatch control of fuel and energy complex). Now, the volume of waste generation in coal mining is more than $98 \%$ the total amount of waste generated in the region. The environment of Kemerovo region is one of the most polluted in the Russian Federation. It is characterized by an intensive anthropogenic load, strong water and air pollution.

Kuzbass has a number of challenges that prevent its sustainable development, which are the following: the high share of the commodity sector in the regional economy, the revenues of the region depend on commodity markets, the lack of infrastructure, reduction of the population due to migration and natural decline, imbalance in the labor market due to the outflow of workforce, high mortality rates among the working-age population, and a strong anthropogenic load.

The Strategy of socio-economic development of the Kemerovo region for the period up to a 2035 determines the solution of problems to provide the sustainable development of the region. The main goal is to get a faster pace of development and competitiveness of the economy and social sphere, as well to achieve leading positions in the quality of life and the human capital development. The solution of related problems in the main directions of strategic development of the region will allow to achieve these goals. The strategic directions are the following:

1. Increasing the attractiveness of the region for the population and target groups of migrants

2. Modification of the system of secondary vocational and higher education under the future changes in the labor market.

3. Modernization of the health care system according to the long-term demographic challenges, the dynamics of the settlement system. The introduction of the latest professional and management technologies in the healthcare system.

4. Diversification of the economy, reducing dependence on mining.

5. Ensuring the needs of the residents in comfortable and safe housing, modern public spaces and transport infrastructure.

6. Ensuring equal opportunities for residents to quality health, education, sports, cultural infrastructure.

7. Creation of a system of incentives for the exploitation of regional minerals on the principles of environmental management and sustainable development.

8. Creation of a system of incentives for the increase of investments in fixed assets aimed at environmental protection and rational use of natural resources.

9. Increase of investment attractiveness of the region for business due to minimizing governmental barriers.

10. Use of the development potential of domestic and foreign markets (export or interregional demand for traded goods).

\subsection{China's experience}

The coal mining industry is the main driving force of socioeconomic development in southwest China. For example, the Beipan River Basin in Guizhou Province claims half of China's coal reserves. Due to its abundant coal deposits, coal mining and coal-fired power generation have become the main pillars of socioeconomic development in the Beipan River Basin.

In 1994, China published its national Agenda 21 action plan for sustainable development. Around this time, sustainable development was set down as China's basic national strategy [5]. For Guizhou Province, as well as other coal mining regions, this resulted in the closure of obsolete, unprofitable and dangerous mines. In 1994 there were 
75000 coal mines in China, by 2013 only 15000 remained open [6]. Mining safety, environmental protection, and resource conservation have been decisive considerations for the closures, but also shortages of financial capital, technology, skilled workers and proper management. As a result, their operations had low recovery rates, poor safety records, and the mines suffered heavy environmental damage. National laws and policies related to mining safety and environmental production obliged mines to fulfill the requirements on sustainable mining. If they will violate at least one requirement would be closed, irrespective of size (big or small). If they are to survive, the coal mines must implement both positive initiatives and measures for sustainable mining.

Today, under China's WDS, the Basin has experienced rapid urban development, expansion of transportation, energy, and tele-communication networks, and ecological restoration $[7,8]$. The region can become a territory of socio-economic growth and environmental development; it can realize the sustainable development strategy in southwest China. But there are some challenges and to achieve these goals they need to be solved [6].

First, there is poor air and water pollution control, it is a common problem in China. There is a lack of responsibility to manage waste post-decommission of mines. After the mines close, no one does to gangues reclamation and revegetation of the mining sites. For this reason, pollution continues for long time after the mining ceases. The governments do not develop any laws for the post-decommissioning of mines management and for managing coal stockpiles, dumps of gangues and sludge, and for recycling waste water. Also, some small coal mines lack abilities for waste processing.

Second, the scale for recycling of natural resources is too small. Employing a circular economy approach to developing new products from their waste has a small volume. The reason is in small markets and insufficient investment.

Third, there are more socio-economic and environmental pressures on the coal industry. Different measures for economic transformation, structure adjustment, and technology innovation are carried in China, because the government commits to sustainable development, anti-climate change, and reduction of air pollution. Also, energy efficiency, renewable and clean energy technologies are developing rapidly. As a result, mines reduce the coal production, into the extracting regions social and economic tensions are created. China decided to cut its coal capacity by 500 million tons by 2020 and the coal mines in southwestern China will not be an exception. This will render 1.3 million coal industry workers unemployed [6]. Guizhou is one of the poorest parts of China, although it sits atop large reserves of coal [6]. The problem can be solved by increasing the coal production, but in formulating a new sustainable development plan to catch up with the rest of the country, it is relying more on imported energy to fulfil the various anti-pollution.

In the 13th five-year plan (2016-2020) for economic and social development of the People's Republic of China the Guizhou province concepts of development will continue in the following strategic directions [9]:

1. Promotion of the development of comprehensive big data experimental zones.

2. Building coal seam gas industrial bases; also accelerate the exploration and exploitation of shale gas.

3. Carrying out major projects, including water control and water source projects.

4. Creating more growth poles to support regional development, promote the development of the urban agglomerations, establish sound mechanisms for coordinating the development of city clusters and promote coordination in industrial division of labor, infrastructure, ecological conservation, and environmental improvement.

5. Implementing investment projects aimed at improving regional infrastructure, social facilities, as well as providing quality education and health care.

6. Promotion of ecological restoration and environmental governance. 


\subsection{India's experience}

In India, coal constitutes a major source of energy as more than $70 \%$ of electricity in the country is generated through thermal power plants [10]. Let's proceed to the impact of coal mining on the socio-economic well-being in the Indian state of Odisha. Odisha has the second largest coal deposits in India and the mining sector contributing significantly to the state GDP, but about $60 \%$ of its population continues to depend on agriculture and ancillary sectors [10]. In recent years, the Government of Odisha has undertaken various measures to promote mining-based industrialization, which have helped achieve phenomenal economic growth and an increase in employment in the mining sector. The extraction

of minerals, associated activities and rapid industrialization have caused serious environmental problems; including air and water pollution, degradation of cultivable land, deforestation and loss of biodiversity. Hota and Behera [10] used the capital approach to sustainable development identifying five broad categories of capital [11, 12]: physical capital, financial capital, natural capital, human capital, and social capital. This approach is based on the natural capital that is allowed to be depleted or degraded, but it must be offset by equivalent or greater increases in other forms of capital. The most important problem is to determine regarding the degree of substitution between natural capital and other forms of capital [10].

Now, coal mining is the most important extractive industry in Odisha, and most of the mines are located in forest areas of the state, which harmed the local ecosystem. Mining is in rural areas, where agriculture and allied activities are the main sources of livelihoods for local people. Extraction of coal has serious consequences on long-term sustainability of the economy.

First of all topical issues in Odisha, like other India's coal-mining regions, is the environment. Open caste coal mining has serious implications on the local communities, which exposed to coal dust and explosive noise in this region. Mines discharge a huge volume of water during the extraction process, the water table in the area is declining and the water retention capacity of cultivable land is declining over time, there is acute scarcity of water in the summer. Air and water pollution have a negative impact on the health of the local communities, agriculture and biodiversity. One of the adverse environmental impacts of mining is that it causes a variety of diseases that are caused mainly due to pollutants in the air and water bodies. Although mining companies provides free medical facilities, these are limited because the health center slack proper facilities. Often doctors refer patients to other hospitals for treatment.

Besides economic and environmental effects, mining has an impact on social and cultural life of the local community. Due to the shortage of skilled mining workers, many labors come to work from other states, so the population is permanently changing. The increase of non-indigenous people is a threat to the preservation of traditions, culture and religion of the ethnic population. Local residents whose lands are in the extracting areas are displaced, which leads to a conflict between communities and business in Odisha. There is an increase in income disparities between mining and agriculture families, increase in number migrants in search of jobs. This has resulted in many social problems like an increase in crime, alcoholism, addiction, decline in social cohesion and others.

These problems can be solved by joint efforts of the state and business. To provide social and economic benefits to local communities, the corporate social responsibilities (CSR) programs have been implemented in mining companies. In recent years many extracting companies have implemented a variety of CSR programs aimed at enhancing welfare measures of the society, social assistance, addressing of environmental impacts of mines, including:

1. Social ensure for the categorical aid.

2. Financial aid in Resettlement and Rehabilitation (R\&R) program. 
3. Investing in the social and cultural development, education and health.

4. Creation and modernization of infrastructure of cities and settlements.

5. Protecting the environment and maintaining ecological balance.

6. Providing equal opportunities for residents to exercise their right for support under CSR programs.

Expenditure on CSR activities has increased every year, but legal bottlenecks hinder their implementation. It is necessary to develop regulatory acts in sustainable development for the extracting companies. [10].

\subsection{United States of America experience}

The United States of America (USA) ranks first in the world in coal reserves that are explored; the total volume of which is estimated at 3.6 trillion tons, of which 477 billion are ready for mining. The state of Wyoming has been the leader in coal mining since 1986 . Wyoming mines operate more economically and efficiently than ever and remain the leaders of the US coal industry, producing about $40 \%$ of the country coal [13]. Coal is the second-largest cash stream for the state and has stimulated the state's economy for decades, but the moving away from coal and transition to alternative energy sources has led to a number of social and economic problems.

The ups and downs experience of the city Gillette, WY, often called "the nation's energy capital", is dependent on the market conditions of competitive markets. In the last decade, the volume of coal mined annually has been reduced and as a result in the region massive layoffs, budget decreases, purchasing power of the population decrease, and business activity decrease followed causing socio-economic tensions in the region.

Awareness of the deep financial dependence on the coal industry, as well instatement of the U.S. EPA's Clean Power Plan expected to reduce carbon dioxide emissions from power plants $32 \%$ below 2005 levels by 2030 [15] throughout the country encourage the local government to search for alternate solutions to this problem.

One of these solutions was a decision by the city and county to begin investing a sizable portion of revenues from the energy sector back into services for the community. Over the years they have invested in themselves and developed infrastructure with new rehabilitation and recreation centers, and with expanding community college and dorms. With help from a grant from the Wyoming Business Council, a business-incubator center has been built. In addition, city is developing the rail and auto infrastructure, mastering the technology of coal advanced processing and alternative use.

The Energy Capital Economic Development Corporation has developed a strategy to diversify the regional economy by using the mechanisms of public-private partnership. The district economic development plan has four levels, including the so-called "building blocks" [14]. The first two levels are the basis for the last two. Legislative, local and state economic development efforts should provide a consistent strategy to stimulate the development of the private sector of companies that provide above average wages, create primary jobs, diversify the economy and generate tax revenues. Legislative and economic policies, sustainable development efforts are carried out in the following areas:

Level 1: "Leadership, civil development and public policy." Minimization of government barriers to constructive business, while creating an environment in which business can flourish and more effectively meet the needs of society. Taking into account the fact that economic development initiatives and policies are more likely to succeed if they rely on existing foundations, and that policies should be aimed at increasing Wyoming's competitiveness.

Level 2 includes three blocks: "Quality of Life", "Human Resource Potential" and "Infrastructure". At this stage, the resource conditions for business operation are being 
created: unhindered access to communal resources, information and communication resources, expansion and creation of a new infrastructure. Equally important is to ensure the quality of life: affordable and high-quality education, medical care, opportunities for recreation and entertainment, operational and uninterrupted operation of public services. The block "Human Resource Potential" means providing the economy with highly qualified personnel in the required quantity.

Level 3 consists of two blocks "Existing business development" and "Entrepreneurship development". Expanding or improving the competitiveness and productivity of existing industries, investments in facilities, goods or services create positive economic activity.

Level 4 "Attracting new companies": by attracting new employers' creation of new employment opportunities are increased, employment of existing firms and support for start-up enterprises are increased, tax revenues to the budget are increased. Attracting new industries is one of the main means of diversifying the economy.

On the example of Gillette, it is clear that the model of economic diversification and avoiding coal dependence is possible in the direction of alternative use of coal, the use of advanced processing technologies, and the development of innovative approaches to the use of "black gold". For example, a company, Atlas Carbon LLC, specifically for Gillette, developed a business plan that provides for alternative use of coal - in this case, the production of activated carbon, rather than burning it for energy [15]. It is noteworthy that the new company uses the infrastructure of a closed coal mine. The state has opened a test center for studying the processes of capturing and storing carbon emissions at thermal stations, finding ways to burn coal without greenhouse gas emissions. Despite the fact that carbon sequestration remains economically unviable due to unresolved questions about the long-term underground storage of carbon, scientists are not going to abandon the idea of "clean coal".

\section{Conclusion}

Today the big question should not be whether coal can ever be "clean", but whether it can be clean enough to support sustainable development. Another major question is whether coal and other mining activities can be sufficiently sustainable to meet people's need for minerals, and to prevent environmental degradation for generations to come. In the minerals sector, sustainable development means that investments in minerals projects should be financially profitable, technically appropriate, environmentally sound and socially responsible. The success of sustainable coal mining will largely depend on sound government guiding ideology on development, strict enforcement of laws and policies, improved environmental awareness in the public, and positive corporate social responsibility.

\section{References}

1. S. Kinnear, B. Miles, Managing mining communities and sustainable development: a central Queensland case study (SEGRA conference, 2015).

2. F. Jonson, QGMJ, 116:1, 1 (2018)

3. A.M. Esteves, F. Vanclay, 29, 137-145 (2009)

4. V. Kopein, E. Filimonova, I. Kudryashova, K. Demidenko, E3S Web Conf., 41, 04036 (2018)

5. K. Zhang, Z. Wen, J. Environ. Manag., 88, 1249-1261 (2008) 
6. X. Yu, Environmental Development, 21, 77-86 (2017)

7. X. Yu, Int. J. Environ. Stud., 72, 132-145 (2015)

8. Zhang, Y., An, Y., Ma, L., Li, X., Prog. Geogr. 31, 878-884 (2012)

9. The $13^{\text {th }}$ five-year plan for economic and social development of the People's Republic of China (NDRC, Beijing, 2016)

10. P. Hota, B. Behera, Miner Econ, 29, 1-13 (2016)

11. C. Ashley, D. Carney, Sustainable livelihoods: Lessons from early experience (DFID, Washington, 1998)

12. Sustainable Livelihoods Guidance Sheet, Department for International Development (DFID, Washington, 1999)

13. Wyoming coal. September 2018 Concise guide (Wyoming Mining Association, Wyoming, 2018)

14. Energy Capital Economic Development. URL: http://www.energycapitaled.com/about/membership-drive/

15. B. Patterson, Can Wyoming's Biggest Coal Town Create a New Future? (Scientific American, Wyoming, 2016) 